\title{
Conditional Cash Transfers, Adult Work Incentives, and Poverty
}

\author{
Emmanuel Skoufias \\ The World Bank \\ and \\ Vincenzo di Maro \\ University College London
}

\begin{abstract}
Conditional cash transfer (CCT) programs aim to alleviate poverty through monetary and inkind benefits, as well as reduce future incidence of poverty by encouraging investments in education, health and nutrition. The success of CCT programs at reducing poverty depends on whether, and the extent to which, cash transfers affect adult work incentives. In this paper we examine whether the PROGRESA program of Mexico affects adult participation in the labor market and overall adult leisure time, and we link these effects to the impact of the program on poverty. Utilizing the experimental design of PROGRESA's evaluation sample, we find that the program does not have any significant effect on adult labor force participation and leisure time. Our findings on adult work incentives are reinforced further by the result that PROGRESA leads to a substantial reduction in poverty. The poverty reduction effects are stronger for the poverty gap and severity of poverty measures.

JEL classification: J22; O12; C21

Keywords: Adult Work Incentives; Conditional Cash Transfers; Difference-in-Differences; Mexico; Poverty Measures; PROGRESA; Randomized design.

World Bank Policy Research Working Paper 3973, August 2006

The Impact Evaluation Series has been established in recognition of the importance of impact evaluation studies for World Bank operations and for development in general. The series serves as a vehicle for the dissemination of findings of those studies. Papers in this series are part of the Bank's Policy Research Working Paper Series. The papers carry the names of the authors and should be cited accordingly. The findings, interpretations, and conclusions expressed in this paper are entirely those of the authors. They do not necessarily represent the views of the International Bank for Reconstruction and Development/World Bank and its affiliated organizations, or those of the Executive Directors of the World Bank or the governments they represent.
\end{abstract}

Corresponding author: Emmanuel Skoufias, World Bank, 1818 H Street NW, Washington, D.C. 20433-USA. Tel: (202)458-7539. Fax: (202) 522-3134. Email: eskoufias@worldbank.org. Acknowledgements: The authors are grateful to Claudia Aburto for excellent research assistance and to Alessandro Tarozzi for useful suggestions. 


\section{Introduction}

Mean-tested conditional cash transfer (CCT) programs are increasingly popular in developing countries as a useful tool for poverty alleviation. Examples of such programs include PROGRESA/Oportunidades in Mexico, Bolsa Familia in Brazil, Bono de Desarrollo Humano in Ecuador, Familias en Accion in Colombia, PRAF in Honduras, PATH in Jamaica, and Red de Proteccion Social (RPS) in Nicaragua, among others. Targeting their benefits directly to populations in extreme poverty, primarily in rural areas, such programs aim to alleviate current poverty through monetary and in-kind benefits, as well as reduce future levels of poverty by encouraging investments in education, health and nutrition.

The success of CCT programs at reducing current poverty depends on whether, and the extent to which, cash transfers affect adult work incentives. In all of the programs mentioned above, once a household is selected as eligible for the program, usually through geographic targeting or household level means-testing, or both, the level of benefits is not affected by the work decisions of the household members or the income level of the household. Thus, the main effect of CCT on the labor supply of adults may be a pure income effect. ${ }^{1}$ This is in contrast to most welfare programs in the US and Canada, that have explicit disincentives to work. For example, in the Aid to Families with Dependent Children (AFDC) in the US, the level of benefits is affected by work decisions as work income is effectively taxed by reducing the level of benefits provided.

The extent to which the transfers of CCT programs result to significant income effects on adult leisure and consumption can only be determined empirically. The incentive effects of welfare programs on labor supply have been the subject of intense scrutiny primarily in the

\footnotetext{
${ }^{1}$ In most CCT programs the eligibility status of beneficiary households is, in theory, re-examined every few years. For example, in the PROGRESA program of Mexico, the eligibility status of households was supposed to be reviewed within three years after a household's entry into the program. In fact, more than five years elapsed before any effort was made to revise the list of beneficiaries.
} 
U.S., the U.K. and Canada (e.g., Stafford, 1985; Moffitt, 1992; Blundell and MaCurdy, 1999; and Widerquist, 2005). In developing countries, however, the evidence regarding the labor supply responses of adults to transfer programs is quite scarce. The study of Sahn and Alderman (1996), one of the rare studies in this topic, suggests that the labor supply effect of a rice subsidy program in Sri Lanka is significantly large. Yet, in a recently published ex-ante microsimulation study of the impact of the Bolsa Escola program on poverty in Brazil, the income effect of the transfers on adult labor supply is assumed to be negligible (Bourguignon, Ferreira, and Leite, 2003).

Our paper sheds light on these issues using data from a large conditional cash transfer program in the poor rural areas of Mexico called PROGRESA (Health, Education and Nutrition Program). With a cash transfer of $20 \%$ of pre-program consumption, PROGRESA has the potential of affecting adult work incentives of both program participants as well as nonparticipants. For eligible households, the income effect of the cash transfer may be weakened by the direct and indirect time costs associated with adhering to the requirements of the program. In addition, the means testing associated with CCT programs may also affect the incentives of both eligible and non-eligible households. On the one hand, individuals who are not eligible for the program's benefits may also have the incentive to work less or earn (or report) a lower income hoping to become eligible for the program in future rounds of expansion of the program. On the other hand, the possibility of future means-tests may impact on the labor supply and investment choices of currently eligible households.

The empirical analysis uses panel data from households surveyed for the purpose of evaluating the impact of PROGRESA on basic indicators of household investment in human 
capital. ${ }^{2}$ A distinguishing feature of the PROGRESA data is that they are based on an experimental design, with randomization of the coverage of the program at the locality level. The empirical methodology consists of comparing conditional means of key outcome variables (such as labor market participation, hours of leisure, and poverty rates) between households living in villages covered by the PROGRESA program (treatment villages) and households living in comparable villages that are out of the program (controls). An additional advantage offered by the design of the sample, is that we can also examine the potential effects of the program on the labor supply of the non-eligible households living in the treated communities (i.e. the communities covered by PROGRESA).

We investigate three main questions. First, we examine whether being eligible or ineligible for PROGRESA benefits affects adult labor force participation. Second, we study the effects of PROGRESA on adult leisure hours. Leisure may be an important determinant of welfare and beneficiary households may choose to increase their welfare by using the cash transfers of the program to "buy" more leisure. Finally, we analyze the impact of PROGRESA on poverty measures based on household income. Poverty measures offer the advantage of being simple, albeit imperfect, summary measures of the effects of the program on the communities with both eligible and ineligible households exposed to the program. Significant labor supply response among households in communities covered by the program may result in small impacts of the program on poverty.

The organization of the paper is as follows. Section 2 describes briefly the PROGRESA program and the data used. Section 3 illustrates the econometric specification and estimation approach behind our results. Section 4 shows and discusses the results regarding the impact of PROGRESA on adult labor force participation and leisure. The impact of PROGRESA on

2 Skoufias (2005) provides a detailed discussion of PROGRESA, the evaluation design and a summary of the impacts of the program estimated by a large team of researchers. 
poverty is studied in section 5 , while section 6 concludes.

\section{A Brief Description of PROGRESA and of the Data Used}

PROGRESA, initially implemented by the Mexican Federal government in 1997, adopts an integrated approach to combating the different causes of poverty by intervening simultaneously in the areas of health, education and nutrition. By the year 2004, the program which was renamed Oportunidades, included nearly 5 million families in 72,345 localities in all

31 states. The total annual budget of the program in 2004 was around US $\$ 2.5$ billion, or $0.3 \%$ of the gross domestic product.

The education component of PROGRESA is designed to increase school enrollment among youth in Mexico's poor rural communities by making education grants available to pupils' mothers, who are then required to have their children attend school regularly. In localities where PROGRESA currently operates, households that have been characterized as poor, and have children enrolled in grades 3-9, are eligible to receive these educational grants every two months. The levels of these grants were determined taking into account, among other factors, what a child would earn in the labor force or contribute to family production. The educational grants are slightly higher at the secondary level for girls, given their propensity to drop out at earlier ages. Every two months, confirmation of whether children of beneficiary families attend school more than $85 \%$ of the time is submitted to PROGRESA by school teachers and directors, and this triggers the receipt of a bi-monthly cash transfer for school attendance.

In the area of health and nutrition, PROGRESA brings basic attention to health issues and promotes health care through free preventative interventions, such as nutritional supplements, and education on hygiene and nutrition as well as monetary transfers for the purchase of food. Receipt of monetary transfers and nutritional supplements are tied to 
mandatory health care visits to public clinics. This aspect of the program emphasizes targeting its benefits to children under five, and pregnant and lactating women, and is administered by the Ministry of Health and by IMSS-Solidaridad, a branch of the Mexican Social Security Institute, which provides benefits to uninsured individuals in rural areas.

Nutritional supplements are given to children between the ages of four months and two years, and to pregnant and breast-feeding women. If signs of malnutrition are detected in children between the ages of 2 and 5, nutritional supplements will also be administered. The nutritional status of beneficiaries is monitored by mandatory visits to the clinic and is more frequently monitored for children five years of age and under, pregnant women and lactating women. Upon each visit, young children and lactating women are measured for wasting (weight-for-height), stunting (height-for-age), and weight-for-age. An appointment monitoring system is set up and a nurse or doctor verifies adherence. The health care professionals submit every two months certification of beneficiary visits to PROGRESA, which triggers the receipt of the cash transfer for food support.

The average monthly payment, distributed every two months to the mothers in beneficiary families amounts to $20 \%$ of the value of monthly consumption expenditures prior to the initiation of the program. ${ }^{3}$ Working counter to this transfer are the direct and indirect costs associated with participation in the program. For example, one of the conditions of the PROGRESA program is that households eligible for the program were required to stop receiving benefits from other pre-existing programs such as Niños de Solidaridad, Abasto Social de

\footnotetext{
3 The average monthly transfers during the twelve-month period from November 1998 to October 1999 are around 197 pesos per beneficiary household per month (expressed in November 1998 pesos). The calculation of this average includes households that did not receive any benefits due to non-adherence to the conditions of the program, or delays in the verification of the requirements of the program or in the delivery of the monetary benefits. On average, households receive 99 pesos for food support, and 91 pesos for the educational grant. For more details, see Hoddinott and Skoufias (2004)
} 
Leche, de Tortilla and the National Institute of Indigenous people (INI). ${ }^{4}$ In addition to these direct costs, there are some indirect costs associated with complying with the program's requirements. Such costs include the time costs of taking children to school and to health center, waiting in line at the health center, attending educational seminars on nutrition and hygiene, and traveling to the localities where payments are being distributed.

The data used in this paper consist of the sample of communities and households surveyed between November 1997 and November 1999, for the purposes of the evaluation of the PROGRESA program. In order to obtain a credible evaluation of the potential impact of the program the PROGRESA administration decided to adopt an experimental design that allows one to compare households before and after the initiation of PROGRESA with similar households that were not yet covered by the program. Specifically, the full sample used in the evaluation of PROGRESA consists of repeated observations (panel data) collected for 24,000 households from 506 localities in the seven states of Guerrero, Hidalgo, Michoacan, Puebla, Queretaro, San Luis Potosi and Veracruz. Of the 506 localities, 320 localities assigned to the treatment group (where PROGRESA was in operation) and 186 localities were assigned as controls. ${ }^{5}$ As originally planned the localities serving the role of a control group started receiving PROGRESA benefits by December 1999.

The selection of beneficiaries into PROGRESA was a two stage process (Skoufias et al. 2001). In the first stage, using national census data, poor communities with schooling and health infrastructure were identified. In the second stage, households within the selected poor

\footnotetext{
${ }^{4}$ Before the establishment of PROGRESA, previous government interventions in the areas of education, health and nutrition in the rural sector of the country consisted of many programs each intervening separately in health, education or nutrition with little prior coordination or consideration of the potential synergies that could result from a better coordinated and simultaneous intervention.

${ }^{5}$ Behrman and Todd, (1999) conducted a careful investigation of the extent to which the selection of localities into treatment and control groups can be considered as random. Their analysis did not reveal any significant differences between village means for more than 300 variables in treatment and controls.
} 
communities were classified as eligible or ineligible based on the socioeconomic data collected by a census of all the households residing in the communities to be covered by the program. On average, in the evaluation sample, $78 \%$ of the households were classified as eligible for program benefits. However, the fraction of households that actually ended up receiving the PROGRESA cash transfers during the two-year interval covered by the evaluation sample is just under $65 \%$, due to administrative errors and delays in the final registration of beneficiary households. ${ }^{6}$

The 1997 baseline household census called ENCASEH (Encuesta de Caracteristicas Socioeconomicas de los Hogares) was followed by a number of socio-economic household surveys (Encuesta de Evaluación de los Hogares or ENCEL) designed to collect information for the evaluation of PROGRESA. The first evaluation survey took place in March 1998 before the initiation of benefits in May 1998. The remaining surveys were conducted after beneficiary households in treatment villages started receiving benefits from PROGRESA. One round of surveys took place in November 1998, which was well after most households received some benefits as part of their participation in the program. The next two waves took place in June 1999 and November 1999. A number of core questions about the demographic composition of households and their socioeconomic status were applied in each round of the survey.

Data used in this paper are drawn from four rounds. The first round (R1) that took place in November 1997, the second round (R2) in November 1998 survey, the third round (R3) in June 1999, and fourth round (R4) that took place in November 1999.

The November 1997 ENCASEH survey as well as the November 1998, June 1999, and November 1999 ENCEL surveys collected detailed information on income earned or received from a variety of sources for each individual in the household. ${ }^{7}$ The survey instrument used to

\footnotetext{
${ }^{6}$ For more details see Skoufias (2005).

7 The March 1998 baseline survey was not used because it did not include household income and labor supply information for adults.
} 
collect individual and household income for these various sources changed significantly beginning with the November 1998 survey. With this caveat in mind it should be noted that a serious effort was made to maintain comparability of income by source across the survey rounds. The various sources of income (excluding the PROGRESA cash transfers) were transformed into monthly income and then aggregated into 4 main sources of income: labor income; income from self employment (such as income from sewing, food preparation, construction or carpentry, commerce, produce transportation, repairs and laundry or cooking); other income (such as pensions, interest income, rents and community profits); and government transfers (such as educational scholarships from Niños de Solidaridad, benefits from Instituto Nacional Indigenista (INI), PROBECAT, Empleo Temporal and Procampo).

The income data by source are useful at quantifying the direct costs associated with participation in the PROGRESA program. Children can contribute income to families by working for wages or by being recipients of cash transfers from other government transfer programs excluding PROGRESA. Figure 1 presents how the income contributed to families by children between ages 8-17 evolved across different survey rounds in the treatment and control villages (using only eligible households E=1). Panel (a) in Figure 1 reveals that the total (labor + other) income (excluding PROGRESA cash transfers) beneficiary families received from children declined in both treatment and control localities since the initiation of PROGRESA in November 1998. The mean total income contributed by children in November 1998 is slightly lower among treatment villages compared to the control villages and the gap gets even bigger by the June 1999 round. By November 1999, this gap is completely eliminated as control households are already incorporated into PROGRESA. ${ }^{8}$ Panels (b) and (c) in the same figure

\footnotetext{
${ }^{8}$ Note that control households started receiving cash benefits in December 1999. Households are first incorporated into PROGRESA, meaning that they are given all the necessary forms and informed of all the program requirements. A few months later, the cash benefits are sent out by the PROGRESA
} 
break down total income from children into its two components, i.e., income from labor and other income that consists mainly of government transfers. These graphs reveal that the differences in mean total income from children in beneficiary households and eligible households in control localities are primarily due to drops in the child-related income beneficiary families received from other government programs. It also appears that there are no significant differences in the labor income of children from beneficiary households in treatment localities and the labor income contribution of children in eligible households in control villages.

In addition to the potential income losses from children's work and benefits, households receiving PROGESA benefits are also required to give up benefits from programs like Abasto Social de Leche, de Tortilla and the National Institute of Indigenous people (INI). Figure 2 makes clear that among beneficiary households (i.e. those that received any PROGRESA benefits between May 1998 and November 1999 in the treatment villages) the incidence of benefits received from DIF, Ninos de Solidaridad and Abasto Social de Leche decreased dramatically. In combination the preceding discussion suggests that the effect of PROGRESA on household income and poverty may not be adequately summarized by the size and incidence of the cash transfers.

\section{Econometric specification and estimation}

We begin with a brief discussion of the estimation approach that underlies our estimates of the impact of PROGRESA on labor force participation, leisure time and poverty rates.

The estimation of the impact of PROGRESA (for labor force participation and poverty rates) is based on the difference-in-differences estimator. This estimator is based on comparing

administration headquarters. 
differences between the treatment and control groups before and after the start of the PROGRESA program. It offers the advantage that any pre-program differences between the treatment and control group are eliminated in the estimation of impacts. Under the assumption that any unobserved heterogeneity between the treatment and control groups is fixed over time, the difference-in -differences estimator (2DIF, discussed in detail below) eliminates this heterogeneity. Specialized empirical specifications are implemented for the labor force participation and poverty estimation and are discussed below. We use also a number of control variables which may be useful for reducing any remaining statistical bias.

To begin with, consider the case where there are data available for treatment and control households before and after the start of the program. ${ }^{9}$ Restricting the sample to eligible households only $(E=1)$, the following regression equation defines a model that can nest various "difference" estimators allowing for controlling for individual, household and locality observed characteristics:

$$
\begin{aligned}
& Y(i, t)=\alpha+\beta_{R 2}(R 2)+\beta_{R 3}(R 3)+\beta_{R 4}(R 4)+\beta_{T} T(i)+ \\
& \beta_{T R 2}(T(i) * R 2)+\beta_{T R 3}(T(i) * R 3)+\beta_{T R 4}(T(i) * R 4)+\sum_{j=1}^{J} \theta_{j} X_{j}(i, t)+\eta(i, t) .
\end{aligned}
$$

$Y(i, t)$ denotes the value of the outcome indicator of interest for household, individual or population $i$ in period $t, \alpha, \beta$, and $\theta$ are fixed parameters to be estimated, $T(i)$ is an binary variable taking the value of 1 if the household resides in a treatment community and 0 otherwise (i.e., for control communities), R2, R3, and R4 are a binary variables equal to 1 for the second, third and fourth rounds of the survey respectively, and equal to zero otherwise. Note that the first round is the baseline round prior to the initiation of the program. The vector $X$

\footnotetext{
${ }^{9}$ It is assumed that there is only one observation after the start of the program for expositional simplicity. The empirical analysis below includes a binary variable and an interaction term with $\mathrm{T}$ for each round of the survey after the start of the program.
} 
summarizes household (and possibly village) characteristics and $\eta$ is an error term summarizing the influence random disturbances.

To better understand the preceding specification it is best to consider the case of only two rounds: one before the initiation of the program and the other after the start of the program (e.g. round 2 or $\mathrm{R} 2=1,0$ otherwise). One may then divide the parameters into two groups: one group summarizing differences in the conditional mean of the outcome indicator before the start of the program (i.e., $\alpha, \beta_{T}$ ) and another group summarizing differences after the start of the program (i.e., $\beta_{R}$, and $\beta_{T R}$ ). Specifically, the coefficient $\beta_{T}$ allows the conditional mean of the outcome indicator to differ between eligible households in treatment and control localities before the initiation of the program whereas the rest of the parameters allow the passage of time to have a different effect on households in treatment and control localities. For example, the combination of parameters $\beta_{R}$ and $\beta_{T R}$ allow the differences between eligible households in treatment and control localities to be different after the start of the program.

Specifically, given the preceding specification, the conditional mean values of the outcome indicator for treatment and control groups before and after the start of the program are as follows:

$$
\begin{aligned}
& {[E(Y \mid T=1, R 2=1, \mathbf{X})]=\alpha+\beta_{T}+\beta_{R}+\beta_{T R}+\sum_{j} \theta_{j} X_{j}} \\
& {[E(Y \mid T=1, R 2=0, \mathbf{X})]=\alpha+\beta_{T}+\sum_{j} \theta_{j} X_{j}} \\
& {[E(Y \mid T=0, R 2=1, \mathbf{X})]=\alpha+\beta_{R}+\sum_{j} \theta_{j} X_{j}} \\
& {[E(Y \mid T=0, R 2=0, \mathbf{X})]=\alpha+\sum_{j} \theta_{j} X_{j}}
\end{aligned}
$$

The advantage offered by the 2DIF estimator is that it provides an estimate of the impact of the program that is net of any pre-program differences between treatment and control households and/or any time trends or aggregate effects in changes of the values of the outcome indicator. By comparing before and after differences between treatment and control households 
(or differences between treatment and control households after and before the program) one is able to get an estimate of the impact of the program (summarized by the single parameter $\beta_{T R}$ ).

$$
\begin{aligned}
2 D I F=[E(Y \mid T=1, R 2=1, \mathbf{X})-E(Y \mid T=1, R 2=0, \mathbf{X})]- \\
{[E(Y \mid T=0, R 2=1, \mathbf{X})-E(Y \mid T=0, R 2=0, \mathbf{X})] }
\end{aligned}
$$

Using the terminology of Heckman, La Londe, and Smith (1999), the parameter $\beta_{T R}$ provides an estimate of the "intent to treat effect," which is inclusive of the operational efficiency or inefficiency of the program implementation. Thus, $\beta_{T R}$ provides a lower bound estimate of the impact of the program on those who actually receive the treatment (or of "the effect of the treatment on those who actually received the treatment").

The availability of repeated observations on non-eligible households in treatment areas before and after the start of the program also offers the opportunity to examine the potential effects of the program on the non-eligible households residing in the treatment communities. For example, non-eligible households in treatment localities may alter their behavior (e.g., work less or withdraw their children from school) in anticipation that such actions may qualify them for the program. An evaluation of the extent to which the program has had some indirect effects on the outcome indicator among non-eligible households in treatment areas can also be conducted by estimating a regression similar to (1) but restricted to the sample of non-eligible households $(\mathrm{E}=0)$.

Note that $\beta_{T}$ is expected to be insignificantly different from zero (that is, pre-program differences prior to program implementation are expected to be zero) and the interaction terms represent the impact of being in a treatment community on work participation after program implementation. The different intercept $\alpha$ terms capture the point that participation in work may vary (for reasons unrelated to PROGRESA) during the first round of the sample. 
In estimating the impact of the program on adult leisure time, we are limited by the fact that there is only one round of data on time allocation (June 99). Given this constraint we estimate the model:

$$
L(i)=\alpha_{0}+\beta_{T} T(i)+\sum_{j=1}^{J} \beta_{j} X_{j}(i)+\varepsilon_{i}
$$

where $L(i)$ measure leisure time of individual $i, T(i)$ represents a binary variable equal to 1 if individual $i$ lives in a treatment community and 0 otherwise, and $X_{j}(i)$ represents the vector of $j$ control variables for individual $i$ (described in section 4). In this model the estimate of the coefficient $\beta_{T}$ is the "cross-sectional difference" (CSDIF) estimate of program impact.

Lastly, the regression equation behind the estimation of the PROGRESA impact on poverty is:

$$
P^{R}(i, t)=\alpha_{0}+\beta_{T} T(i)+\beta_{R} R+\beta_{T R}(T(i) * R)+\eta(i, t)
$$

where the superscript $\mathrm{R}$ represents the round $\mathrm{R}=2,3,4$ and $P^{R}(i, t)$ is the poverty measure (described in section 5) for population of interest $i$ (in our case the entire treatment or control population) at time $t$ and for round R; other objects are defined as above.

Specification (8) reflects the fact that we estimate three different impacts of PROGRESA on the poverty rate between each of the three survey rounds ( $R=2$ Oct $98, R=3$ Jun $99, R=4$, Nov 99) and the first round of the survey ( $R=1$, Oct 97), with the following difference-in-differences estimator (for each R):

$$
\begin{aligned}
2 D I F^{R}=\{E[P \mid T=1, R=1, X]-E[P \mid T=1, R=0, X]\}- \\
\{E[P \mid T=0, R=1, X]-E[P \mid T=0, R=0, X]\} .
\end{aligned}
$$

\section{The impact of PROGRESA on adult labor force participation and leisure} Adult labor force participation 
To estimate the impact on labor force participation, we use the data as our baseline round and three post-program rounds of November 1998, June 1999, and November 1999.

The dependent variable $Y(i, t)$ in equation (1) is specified by a binary variable indicating whether an individual $i$ works in the labor market in period $t$. Specifically, a person is classified as working in the labor market $(Y(i, t)=1)$ if he/she reported that having worked over the previous week (whether paid or unpaid). In addition, we take into account a follow-up question to capture individuals who may engage in informal activities, which the respondent may not have initially considered as work. This question collects information about participation in a) selling a product; b) helping in family business; c) making products to sell; d) washing, cooking or ironing; and e) working in agriculture activities or caring for animals. We also include as working those individuals who respond that they engage in any of these activities. It is important to keep in mind that domestic activities are not included in this definition of work.

We also consider two other outcomes variables, salaried work and non-salaried work and estimate the impact of PROGRESA on each category. The distinction between salaried and non-salaried ${ }^{10}$ work is made through what a worker reports as his/her occupational position. Workers who report that they were daily agricultural workers or non-agricultural employees are considered as salaried workers. All other workers are classified separately and include selfemployed workers, business owners, unpaid workers and ejidatarios.

Equation (1) is estimated separately for males and females. In addition, we conduct the empirical analysis separately for 5 age group (ages 18 to 24,25 to 34,35 to 44,45 to 54 and 55

\footnotetext{
${ }^{10}$ In preliminary analysis, we considered separating non-salaried workers between self-employed workers and unpaid family workers. Nevertheless, the proportions of individuals participating in each of these activities are quite small for all age groups, and the distinction between these activities is often blurred so that we prefer to aggregate these groups in the impact analysis.
} 
and over) and for the group of all adults. In general the labor force participation of women of all ages is quite low (for no age group do overall labor force participation rates exceed $18 \%$ ). In addition, the majority of women who do work tend to participate in unsalaried activities: this is particularly true of women over the age of 35. It is interesting to note the decreasing relative participation in salaried work versus unsalaried activities with age of women. Men, on the other hand, show a very high labor force participation rate, over $90 \%$ for men between the ages of 24 and 55. The majority of men are salaried workers, although the percentage in salaried work tends to decrease with age. For male workers over the age of 55, almost half participate in nonsalaried activities.

In particular, our sample includes 183,646 individual observations $(89,207$ observations on adult males and 94,439 observations on adult females) for 4 rounds of the PROGRESA evaluation sample (Nov 97, Oct 98, Jun 99 and Nov 99) that are divided in treatment and control localities. The analysis is first carried on the sample of those who are classified as "poor"11, and thus eligible to receive the program if they live in treatment localities $(E=1)$. We then re-do the same estimation on the sample of those who are classified as non-eligible $(E=0)$.

The vector $X$ in equation (1) consists of individual and demographic composition variables. In particular, we include as individual characteristics his/her age, age squared, marital status, whether he/she is head of the household, speaks an indigenous language, and his/her level of education. The demographic composition variables include the number of children aged 0 to 2 and aged 3 to 5, boys and girls between 6 and 7 years old , 8 to 12, and 13 to 18, men and women aged 19 to 54 and men and women over the age of 55 . At the community

\footnotetext{
11 This is the poor status after the densifcacion, the revision of the eligibility that raised the number of households eligible for the program from $52 \%$ to $78 \%$. It has to be noticed that the fraction of households that actually ended up receiving the PROGRESA cash transfers during the two-year interval covered by the evaluation sample is just under $65 \%$, due to administrative errors and delays in the final registration of beneficiary households.
} 
level, the model also contains a variable measuring distance to the "cabecera municipal" which is an indicator of distance to the governing center of the municipality (and likely the largest locality of the municipality).

Given that dependent variable is binary, equation (1) is estimated with a probit model. Table 1 presents the 2DIF estimates (summarized by the parameter $\beta_{T R}$ in equation 1 ) of the impact of PROGRESA on the probability of working of male and female adults for the sample of individuals form eligible households $(E=1) .{ }^{12}$ The clustering of the households within villages implies that the household-specific error terms $\eta(i, t)$ are likely to be correlated within each village (as well as across time). Thus standard errors were estimated taking into account of the clustered nature of the sample. The results are presented showing the initial level of participation in work activities (that is prior to program implementation) and the impact estimates for each round of the survey carried out after program implementation. The impact from each round should be interpreted as the percentage point difference from the pre-program level (not from the previous round). In other words, the estimates reported represent the marginal effects of being in a household eligible for PROGRESA benefits on the probability of being in the labor force. ${ }^{13}$

Beginning with men, the results of the impact of PROGRESA on overall participation levels show little impact. The only exception is for men in the age groups 35 to 54 , for which in the November 1999 round there is a positive and significant increases in the probability of working. The magnitudes of these effects, however, are relatively small, reflecting the already high pre-program participation of men in the labor market.

\footnotetext{
12 The complete set of parameter estimates is available directly from the authors upon request.

13 The estimates reported were obtained using the "dprobit" command in STATA v7.0. They can be easily converted into percentage changes or elasticities by dividing the marginal effect by the pre-program level, both reported in table 1 .
} 
Looking at the decomposition between salaried work and other types of works, there are some impacts, particularly in the November 1998 round the first round after PROGRESA was implemented in these communities. In this round, there is a universal, for all age groups, increase in the probability of working in salaried work and a corresponding decrease in the probability of working in non-salaried work. These effects remain present in the next round of the data (June 1999) only for men aged 25 to 34 and disappear by the fourth round of the survey. The results seem to suggest that, at least initially, families may have used some part of the grants to seek work in salaried activities and to reduce their participation, perhaps, in less profitable family enterprises. This impact, however, appears to disappear over time.

For women, the results show few overall impacts of PROGRESA on participation in the labor market. For women in the age group 45-54, there is a significant reduction in participation according to the first after program round of the ENCEL, although this impact does not hold up over time. As with men, there is also a significant reduction in the probability of participating in non-salaried work activities in the first after program round, but again these effects do not hold up over time. In short, these data do not show particularly significant or lasting effects of PROGRESA on labor market participation. Rather, they are consistent with a story that PROGRESA does not affect participation of men and women.

In table 2 we present the results for the sample of individuals who are classified as noneligible for the program (or $\mathrm{E}=0$ ). Even though these individuals are not in PROGRESA (that only covers the "poor" individuals in treatment localities), the program may have been generating spillover effects; for example, households in PROGRESA localities who are not poor could have revised their labor force participation choices in order to become eligible for the program. However, our results suggest that PROGRESA does not have any significant effect on participation on individuals who are not poor; the only coefficients that are significant (only at 
$10 \%$ level) are all negative, but very small in magnitude.

Leisure

Our measure of leisure time is constructed as a residual, that is as the difference between 24 hours and the time spent on all reported activities. In particular, we use the time use module (present only in the June 1999 round) with information on 18 activities carried out during the previous day; the previous day as reference period is not particularly ideal, as for some individuals, the survey may refer to a day which was not "typical" of normal activities. Additionally, many activities may be activities which are done infrequently (i.e. not daily). The survey was carried out this way as it was thought that a "previous day" reference period would reduce recall bias, given the large number of activities included in the questionnaire. The control variables included are the same of those in the labor force participation estimation (discussed above).

Table 3 presents the CSDIF estimates of the effect of PROGRESA on adult leisure (summarized by parameter $\beta_{T}$ in equation (7)). Note that one hypothesis of the impact of PROGRESA on leisure is that, if the PROGRESA transfers are perceived as strict income transfers, and leisure is a normal good, then one might expect leisure to increase with PROGRESA. Nevertheless, the structure of the grants which reduce the price of schooling of children and thus may reduce the work of children may imply that overall hours dedicated to household production work (previously done by children) might increase. This would then imply that the program would have an ambiguous effect on the leisure time of adults and especially women. For example, it is conceivable that complying with the program's requirements might decrease the leisure time of women, as they attempt to substitute for the 
time children used to allocate in home production activities. ${ }^{14}$

Overall, the results do not show significant impacts of PROGRESA on the leisure time of men or women. There are some small negative impacts of PROGRESA on leisure for men for one age group, namely men aged 18 to 24 , which corresponds to increases in work for this group of men of about 0.3 hours daily, or about 2 hours weekly. Nevertheless, there are no significant impacts on any other age groups for males. The results for women are insignificant in all specifications and for all groups. Accordingly, we can say that there is not much evidence to support the hypothesis that PROGRESA has reduced the leisure time of men and women. There is certainly no evidence to support that leisure time has increased under PROGRESA ${ }^{15}$.

\section{The impact of PROGRESA on poverty}

The results presented so far on the impact of the program on adult labor market participation and leisure suggest that the program has no adverse effects on labor income. Thus, ceteris paribus, the cash transfers received by program beneficiaries are likely to increase household income at least among beneficiary families. However, the extent to which this occurs depends on the size of the direct and indirect costs associated with participation in the program. In addition, the income of non-eligible households may be adversely affected to the extent that non-eligible households believe that a lower household income increases their chances of becoming eligible for the program. Estimating the impact of the program on the poverty rate provides a useful summary measure of how the program affects the income of both eligible and

\footnotetext{
14 Skoufias and Parker (2001) and Schultz (2004) study the impact of PROGRESA on the work time and school attendance of school-age children. In particular, Skoufias and Parker (2001) find significant increases in the school attendance of boys and girls that are accompanied by significant reductions in the participation of boys and girls in work activities.

${ }^{15}$ Note, however, that the results on leisure do not necessarily suggest that there has been no reallocation of time between work activities for adults. For instance, there may have been a substitution towards more time in domestic work and less time in market work. (for results on this issue see Parker and Skoufias, 2000).
} 
non-eligible households in the treatment localities relative to those in the control localities.

The measure of welfare used in our analysis is income per capita. ${ }^{16}$ For households in treatment villages receiving PROGRESA cash transfers, total income per month was adjusted upwards by the cash transfer per month received by the household. The actual amount of cash transfers received per month was obtained from the records of payments sent out each month since May 1998 by the PROGRESA administration headquarters in Mexico City. The monthly income measure calculated for each round of the survey was then converted in November 1998 pesos by dividing by the corresponding adjustment ratio of the national consumer price index.

We calculate different poverty measures using two different poverty lines: the value of the basic food basket (canasta basica) and the median of the per capita value of consumption in November 1998. The first poverty line (basic food basket) yields a poverty rate of $90.1 \%$ in the base year. The median of per capita consumption in November 1998 yields a poverty rate of $59 \%$ which is only slightly below the fraction of the population in the treatment villages that actually received the benefits of the program (see section 2 above).

The choice of a poverty line is a major concern when poverty measures are estimated. We try to deal with this issue by means of a test of stochastic dominance, up to order three, between the distribution of monthly income in treatment and control areas for each round. As far as the program impact on poverty is concerned, stochastic dominance of one distribution on the other can have important implications. For instance, if the distribution of income in treatment areas first-order stochastically dominates that in control areas, this implies that the fraction of poor households (income below the poverty line) will be always smaller in treatment areas than that in control's no matter which poverty line is chosen. Other orders of stochastic

\footnotetext{
16 The absence of reliable information on household consumption prior to the start of the program precluded the use of consumption as a measure of the poverty impacts of the program. For more details on the consumption impacts of PROGRESA see Hoddinott and Skoufias (2004).
} 
dominance will lead to different conclusions that regard other poverty measures (see below). In brief, stochastic dominance is explored here in order to understand whether there is evidence of a program impact on poverty that is robust to choice of a poverty line.

Poverty is measured along the lines suggested by Foster, Greer, and Thorbecke (1984) henceforth (FGT). The FGT poverty measures are summarized by the formula:

$$
P(\alpha)=(1 / N) \sum_{i=1}^{q}\left(\frac{z-y_{i}}{z}\right)^{\alpha},
$$

where $N$ is the number of households, $y_{i}$ is the per capita income of the $i$ th household, $\mathrm{z}$ is the poverty line, $q$ is the number of poor individuals, and $\alpha$ is the weight attached to the severity of household poverty (or the distance from the poverty line). When $\alpha=0$, the FGT measure collapses to the Headcount Index, or the percentage of the population that is below the poverty line. When $\alpha=1$ the FGT measure gives the poverty gap $\mathrm{P}(1)$, a measure of the average depth of poverty. When $\alpha=2$, the FGT index becomes the severity of poverty index. The $\mathrm{P}(2)$ measure assigns more weight to individuals that are further away from the poverty line ${ }^{17}$.

As described in section 3, relying on reported household income allows one to obtain the difference-in-differences (2DIF) estimate of the impact of the program on poverty which compares the change in a poverty measure in treatment villages to the changes in the corresponding poverty measure in control villages. In addition to controlling for macroeconomic shocks common to both treatment and control localities, this estimate allows one to account for any pre-existing differences in poverty between control and treatment localities and thus yield "cleaner" estimate of the impact of the program on poverty.

In Table 4 we present the estimated poverty rates in treatment and control localities in each survey round as well as a difference-in-differences (2DIF) estimate of the impact of

${ }^{17}$ FGT poverty measures are related to stochastic dominance. In particular, first-order stochastic dominance (SD) implies that all $\mathrm{P}(\alpha)$ for $\alpha>0$ are robust to the choice of the poverty line; the same applies for all $\alpha>1$ for second-order SD and for all $\alpha>2$ for third-order SD. 
PROGRESA's cash transfers. The standard errors reported for the Foster, Greer and Thorbecke (1984) poverty indices are calculated using the method proposed by Kakwani (1993). Inspection of the tables reveals that the 2DIF estimates imply that PROGRESA had a significant impact in reducing poverty between November 1997 and November 1999. For example, using the $50^{\text {th }}$ percentile of the value of consumption per capita as a poverty line, suggests that the headcount poverty rate declined by around $11 \%$ in treatment areas between November 1997 and November 1999 (using as base the 60.9\% poverty rate in treatment localities in November 1997). Over the same period, and using as base the corresponding value of the poverty gap and squared poverty gap indices in treatment areas in November 1997, the poverty gap measure declined by $33 \%$, and the severity of poverty measure (squared poverty gap) declined by $55 \%$.

These estimates are remarkably in line with the estimates obtained using ex-ante simulations. These simulations are based on the predicted consumption of each household in the evaluation sample in November 1997 and adding the maximum amount of PROGRESA cash transfers an eligible household could receive assuming full compliance with the program's requirements (see Skoufias et al., 2001). In particular, the results obtained from the simulated impact of PROGRESA's cash transfers show that the headcount ratio is reduced by about $10 \%$ through the supports of PROGRESA. The poverty gap and severity of poverty measures, that place greater weight on the poorest households within the population in poverty, show that the level of poverty according to the poverty gap is reduced by $30 \%$ whereas the severity of the poverty index (squared poverty gap) is reduced by $45 \%$.

Results from our test of stochastic dominance (see details of the test and results in appendix A) add some robustness to the evidence above. In particular, we find that the distribution of income for population of treated households first-order stochastically dominates 
that of control group in round June 1999 and November 1999 (while for round November 1998 we find third-order stochastic dominance; see also figure 3 where we report the estimated $\mathrm{CDF}^{\prime} \mathrm{s}$ and poverty deficit curves $\left.{ }^{18}\right)$. An implication of these results is that in June and November $1999 \mathrm{P}(0)$ (and so $\mathrm{P}(1)$ and $\mathrm{P}(2)$ ) will be always smaller in treatment than in control group regardless of the poverty line chosen.

In conclusion, since we find the strongest evidence of poverty reduction when we analyze poverty gap and severity of the poverty index (poverty gap squared), which put greater weight on the poorest of the poor, both the simulation and the actual ex-post results suggest that the largest reductions in poverty of PROGRESA are being achieved in the poorest of the poor population.

\section{Conclusions}

Conditional cash transfer (CCT) programs aim to alleviate current poverty through monetary and in-kind benefits, as well as reduce future levels of poverty by encouraging investments in education, health and nutrition. The success of CCT programs at reducing current poverty depends on whether, and the extent to which, cash transfers affect adult work incentives.

Based on the experimental design of PROGRESA's evaluation sample, our findings yield a very consistent answer. PROGRESA does not have any significant effect on adult labor supply choices. In particular, the results show that there has been no particular reduction in labor market participation rates, as may have been predicted by some economic models of behavior. There is some evidence that individuals, at least right after they started to receive the transfers,

\footnotetext{
18 The estimated CDF gives the $\mathrm{P}(0)$ for any level of income. Poverty deficit curve is defined as the area under the CDF up to some poverty line. If the poverty deficit curve of one distribution lies above the poverty deficit curve of another, the first distribution will always have more poverty according to the poverty-gap measure, $\mathrm{P}(1)$.
} 
may have used part of the grants to seek work in salaried activities and to reduce their participation in perhaps less profitable family enterprises. This impact, however, appears to disappear over time (see the results for the last round, November 1999). In addition, there is not much evidence to support the hypothesis that PROGRESA beneficiaries use their transfers to "buy" more leisure.

Our findings on adult work incentives are reinforced further by the result that PROGRESA leads to a substantial reduction in current poverty. The poverty reduction effects are stronger for the poverty gap and severity of poverty measures, which put greater weight on the poorest of the poor, and our evidence suggests that these estimated poverty measures are robust to the choice of different poverty lines. As an additional piece of evidence, we notice that our results on the PROGRESA impact on poverty rates are remarkably in line with the $e x$ ante simulated impact of PROGRESA's cash transfers (as in Skoufias, Davis and de la Vega, 2001). Thus, ex-ante simulations that ignore or assume away behavioral responses to the transfer (as in Bourguignon et al, 2003) are likely to provide good estimates of the ex-post impact on poverty. 


\section{References}

Behrman, J., and P. E. Todd. 1999. "Randomness in the experimental samples of PROGRESA (education, health, and nutrition program)". February. Report submitted to PROGRESA. Washington D.C. International Food Policy Research Institute.

Blundell R. and T. MaCurdy, 1999. "Labor supply: A review of alternative approaches," chapter 27 in O. Ashenfelter and D. Card (eds.) Handbook of Labor Economics, vol. 3A. Amsterdam, The Netherlands: North Holland, pp. 1559-1695.

Bourguignon, F., F.H.G. Ferreira and P.G. Leite, 2003, "Conditional cash transfers, schooling, and child labor: Microsimulating Brazil's Bolsa Escola program", World Bank Economic Review, Vol. 17, no. 2 (December), pp. 229-254.

Davidson, R. and J-Y Duclos, 2000, "Statistical Inference for Stochastic Dominance and for the Measurement of Poverty and Inequality", Econometrica, Vol. 68, No.6, 1435-1464

Foster J, J. Greer and E. Thorbecke, 1984 “A class of decomposable poverty measures", Econometrica 52, 761-65

Foster, J. E., and F. Shorrocks, 1988, "Inequality and Poverty Orderings", European Economic Review,32, 654-662

Heckman, J. J, R. La Londe, and J. Smith. 1999. “The economics and econometrics of active labor market programs", chapter 31, in Ashenfelter O. and D. Card (eds.) Handbook of Labor Economics, vol. 3A. Amsterdam, The Netherlands: North Holland, pp. 1865-2097.

Hoddinott J. and E. Skoufias, 2004, "The impact of PROGRESA on food consumption", Economic Development and Cultural Change, Vol. 53, No. 1, October 2004, pp. 37-61

Kakwani, N, 1993. "Statistical inference in the measurement of poverty", The Review of Economics and Statistics, MIT Press, vol. 75(4), pages 632-39.

Moffitt, R., 1992. "Incentive effects of the U.S. welfare system: A review," Journal of Economic Literature, Vol. 30, No. 1 (March), pp. 1-61.

Parker, S. and E. Skoufias, 2000, "The impact of PROGRESA on work, leisure and time allocation", Report submitted to PROGRESA, Washington DC, International Food Policy Research Institute.

Ravallion, M. , 1994, "Poverty Comparisons, Fundamentals of Pure and Applied Economics", Switzerland: Harwood Academic Publishers

Sahn, D., and H. Alderman, 1996. "The effect of food subsidies on labor supply in Sri Lanka," Economic Development and Cultural Change, Vol. 45, (October), pp. 125-145.

Schultz, T.P., 2004. "School Subsidies for the Poor: Evaluating the Mexican Progresa Poverty Program" Journal of Development Economics, vol. 74, no. 1 (June), pp. 199-250.

Skoufias, E., 2005. "PROGRESA and its impacts on the welfare of rural households in Mexico" IFPRI Research Report No. 139. Washington DC, International Food Policy Research Institute.

Skoufias, E., Davis B., and de la Vega S., 2001. “Targeting the poor in Mexico: An evaluation of the PROGRESA selection mechanism," World Development Vol. 29, no. 10 (October), pp. 1769-1784.

Skoufias, E., and Parker S.W., 2001. Conditional cash transfers and their impact on child work and schooling: Evidence from the PROGRESA program in Mexico, Economia, Vol.2, No. 1, Fall 2001, pp. 45-96.

Stafford, F., 1985. "Income-maintenance policy and work effort: learning form experiments and labor market studies," In Hausman J.A. and Wise D.A. (Eds.) Social Experimentation, University of Chicago Press, Chicago, pp. 95-143.

Widerquist K., 2005. "A failure to communicate: What (if anything) can we learn from the negative income tax experiments?" Journal of Socio-Economics, vol. 34, pp. 49-81. 
Table 1 - The impact of PROGRESA on the probability of working among eligible $(E=1)$ adults

\begin{tabular}{|c|c|c|c|c|c|c|c|c|c|c|c|c|c|c|c|c|c|c|c|c|}
\hline \multirow{3}{*}{ Age group } & \multirow{3}{*}{$\begin{array}{l}\text { pre-prog } \\
\text { labor } \\
\text { force }\end{array}$} & \multicolumn{9}{|c|}{ Impact } & \multirow{3}{*}{$\begin{array}{l}\text { pre-prog } \\
\text { labor } \\
\text { force }\end{array}$} & \multicolumn{9}{|c|}{ Impact } \\
\hline & & \multicolumn{3}{|c|}{ Oct. 98} & \multicolumn{3}{|c|}{ Jun-99 } & \multicolumn{3}{|c|}{ Nov. 99} & & \multicolumn{3}{|c|}{ Oct. 98} & \multicolumn{3}{|c|}{ Jun-99 } & \multicolumn{3}{|c|}{ Nov. 99} \\
\hline & & coef. & se & t-stat & coef. & $\mathrm{se}$ & t-stat & coef. & se & t-stat & & coef. & se & t-stat & coef. & se & t-stat & coef. & se & t-stat \\
\hline \multicolumn{21}{|l|}{ All Work } \\
\hline $18-24$ & 0.86 & -0.005 & 0.018 & -0.32 & -0.011 & 0.019 & -0.58 & 0 & 0.019 & 0.04 & 0.18 & -0.022 & 0.016 & -1.3 & $-0.037^{\text {** }}$ & 0.015 & -2.23 & -0.02 & 0.017 & -1.13 \\
\hline $25-34$ & 0.94 & -0.003 & 0.01 & -0.32 & -0.014 & 0.01 & -1.45 & 0.001 & 0.009 & 0.2 & 0.16 & -0.012 & 0.015 & -0.77 & -0.019 & 0.013 & -1.33 & -0.012 & 0.015 & -0.78 \\
\hline $35-44$ & 0.95 & 0.005 & 0.009 & 0.54 & 0.009 & 0.009 & 0.95 & 0.013 & 0.008 & 1.39 & 0.18 & -0.014 & 0.013 & -0.99 & 0.011 & 0.018 & 0.61 & -0.017 & 0.016 & -0.99 \\
\hline $45-54$ & 0.94 & 0 & 0.013 & 0.01 & -0.003 & 0.014 & -0.26 & 0.014 & 0.011 & 1.18 & 0.18 & $-0.038^{\star *}$ & 0.014 & -2.36 & $-0.03^{*}$ & 0.014 & -1.91 & -0.012 & 0.02 & -0.61 \\
\hline $55+$ & 0.78 & -0.008 & 0.019 & -0.44 & -0.02 & 0.023 & -0.89 & 0 & 0.019 & 0 & 0.15 & 0.002 & 0.014 & 0.21 & 0.011 & 0.013 & 0.83 & $0.032^{* *}$ & 0.017 & 1.96 \\
\hline All adults & 0.89 & -0.003 & 0.009 & -0.36 & -0.007 & 0.009 & -0.81 & 0.006 & 0.008 & 0.7 & 0.17 & -0.014 & 0.011 & -1.24 & -0.013 & 0.01 & -1.18 & -0.006 & 0.012 & -0.5 \\
\hline \multicolumn{21}{|c|}{ Salaried work } \\
\hline $18-24$ & 0.64 & $0.04^{*}$ & 0.025 & 1.78 & 0.021 & 0.026 & 0.8 & 0.023 & 0.03 & 0.76 & 0.1 & -0.003 & 0.012 & -0.29 & $-0.026^{* *}$ & 0.011 & -2.08 & -0.016 & 0.011 & -1.34 \\
\hline $25-34$ & 0.7 & 0.034 & 0.025 & 1.27 & $0.037^{*}$ & 0.021 & 1.65 & 0.017 & 0.026 & 0.67 & 0.07 & 0.005 & 0.008 & 0.6 & -0.003 & 0.008 & -0.33 & 0.006 & 0.009 & 0.76 \\
\hline $35-44$ & 0.66 & $0.044^{\star}$ & 0.025 & 1.65 & 0.034 & 0.025 & 1.3 & 0.014 & 0.029 & 0.49 & 0.07 & 0.002 & 0.009 & 0.31 & 0.006 & 0.01 & 0.63 & -0.003 & 0.009 & -0.37 \\
\hline $45-54$ & 0.62 & $0.054^{*}$ & 0.031 & 1.66 & 0.038 & 0.031 & 1.19 & 0.043 & 0.031 & 1.36 & 0.05 & -0.001 & 0.01 & -0.16 & -0.005 & 0.009 & -0.56 & 0.008 & 0.012 & 0.68 \\
\hline $55+$ & 0.43 & 0.04 & 0.034 & 1.18 & 0.025 & 0.031 & 0.79 & 0.019 & 0.033 & 0.58 & 0.04 & 0.005 & 0.007 & 0.77 & 0.006 & 0.008 & 0.85 & $0.013^{*}$ & 0.008 & 1.74 \\
\hline All adults & 0.61 & 0.045 & 0.023 & 1.87 & 0.034 & 0.021 & 1.56 & 0.025 & 0.023 & 1.06 & 0.07 & 0.002 & 0.005 & 0.36 & -0.004 & 0.005 & -0.74 & 0.001 & 0.006 & 0.2 \\
\hline \multicolumn{21}{|c|}{$\begin{array}{c}\text { Self-employed/family } \\
\text { business }\end{array}$} \\
\hline $18-24$ & 0.21 & $-0.035^{\star}$ & 0.018 & -1.8 & -0.017 & 0.02 & -0.85 & 0 & 0.021 & 0.01 & 0.07 & -0.013 & 0.009 & -1.33 & -0.004 & 0.01 & -0.37 & 0.008 & 0.014 & 0.64 \\
\hline $25-34$ & 0.24 & -0.03 & 0.022 & -1.27 & $0.048^{*+t}$ & 0.017 & -2.57 & -0.01 & 0.023 & -0.46 & 0.09 & -0.008 & 0.01 & -0.76 & -0.01 & 0.008 & -1.18 & -0.012 & 0.011 & -1.05 \\
\hline $35-44$ & 0.29 & -0.036 & 0.024 & -1.43 & -0.02 & 0.023 & -0.82 & 0.02 & 0.028 & 0.07 & 0.11 & -0.013 & 0.008 & -1.48 & 0.02 & 0.016 & 1.35 & -0.008 & 0.012 & -0.67 \\
\hline $45-54$ & 0.31 & -0.047 & 0.03 & -1.46 & -0.037 & 0.029 & -1.2 & -0.023 & 0.029 & -0.79 & 0.13 & $-0.022^{*}$ & 0.01 & -2.22 & -0.018 & 0.01 & -1.53 & -0.004 & 0.016 & -0.29 \\
\hline $55+$ & 0.35 & -0.031 & 0.027 & -1.13 & -0.029 & 0.024 & -1.18 & -0.002 & 0.027 & -0.1 & 0.1 & -0.002 & 0.01 & -0.2 & 0.007 & 0.01 & 0.72 & 0.018 & 0.016 & 1.22 \\
\hline All adults & 0.28 & -0.035 & 0.019 & -1.75 & -0.031 & 0.017 & -1.78 & -0.007 & 0.02 & -0.38 & 0.1 & -0.011 & 0.007 & -1.46 & -0.002 & 0.008 & -0.27 & 0 & 0.01 & -0.07 \\
\hline
\end{tabular}

***=significant at $1 \%$ level, ${ }^{* *=}=$ significant at $5 \%$ level, ${ }^{*}=$ significant at $10 \%$ level

See text for more details 
Table 2 - The impact of PROGRESA on the probability of working among non-eligible $(E=0)$ adults

\begin{tabular}{|c|c|c|c|c|c|c|c|c|c|c|c|c|c|c|c|c|c|c|c|c|}
\hline \multirow{3}{*}{ Age group } & \multirow{3}{*}{$\begin{array}{l}\text { Pre-prog } \\
\text { labor force } \\
\text { participation }\end{array}$} & \multicolumn{9}{|c|}{ Impact } & \multirow{3}{*}{$\begin{array}{l}\text { Pre-prog } \\
\text { labor force } \\
\text { participation }\end{array}$} & \multicolumn{9}{|c|}{ Impact } \\
\hline & & \multicolumn{3}{|c|}{ Oct. 98} & \multicolumn{3}{|c|}{ Jun-99 } & \multicolumn{3}{|c|}{ Nov. 99} & & \multicolumn{3}{|c|}{ Oct. 98} & \multicolumn{3}{|c|}{ Jun-99 } & \multicolumn{3}{|c|}{ Nov. 99} \\
\hline & & coef. & se & t-stat & coef. & se & t-stat & coef. & & t-stat & & coef. & se & t-stat & coef. & se & t-stat & coef. & se & t-stat \\
\hline \multicolumn{21}{|l|}{ All Work } \\
\hline $18-24$ & 0.88 & 0.003 & 0.026 & 0.15 & -0.029 & 0.029 & -1.03 & -0.016 & 0.029 & -0.57 & 0.29 & 0.001 & 0.03 & 0.05 & -0.006 & 0.03 & -0.22 & -0.003 & 0.034 & -0.1 \\
\hline $25-34$ & 0.95 & -0.021 & 0.021 & -1.03 & $-0.036^{*}$ & 0.023 & -1.74 & 0.002 & 0.02 & 0.11 & 0.32 & 0.015 & 0.033 & 0.47 & 0.039 & 0.037 & 1.08 & -0.01 & 0.034 & -0.3 \\
\hline $35-44$ & 0.96 & -0.022 & 0.023 & -1.1 & -0.008 & 0.02 & -0.43 & 0.004 & 0.02 & 0.21 & 0.26 & -0.018 & 0.031 & -0.57 & 0.012 & 0.031 & 0.39 & $-0.061^{* *}$ & 0.028 & -1.96 \\
\hline $45-54$ & 0.96 & -0.032 & 0.026 & -1.34 & -0.016 & 0.024 & -0.85 & 0.015 & 0.019 & 0.71 & 0.21 & 0.018 & 0.028 & 0.69 & 0.007 & 0.028 & 0.25 & -0.032 & 0.021 & -1.42 \\
\hline $55+$ & 0.88 & -0.06 & 0.024 & -0.26 & -0.026 & 0.028 & -0.97 & -0.017 & 0.027 & -0.65 & 0.18 & $-0.034^{*}$ & 0.016 & -1.9 & $-0.031^{*}$ & 0.017 & -1.67 & $-0.035^{*}$ & 0.019 & -1.62 \\
\hline All adults & 0.92 & -0.014 & 0.011 & -1.23 & -0.024 & 0.012 & -2.03 & -0.007 & 0.011 & -0.63 & 0.27 & -0.01 & 0.017 & -0.59 & -0.002 & 0.017 & -0.14 & -0.03 & 0.017 & -1.71 \\
\hline \multicolumn{21}{|c|}{ Salaried work } \\
\hline $18-24$ & 0.57 & 0.014 & 0.037 & 0.39 & -0.015 & 0.047 & -0.32 & -0.029 & 0.04 & -0.73 & 0.17 & 0.003 & 0.024 & 0.16 & 0.021 & 0.029 & 0.74 & 0.024 & 0.029 & 0.87 \\
\hline $25-34$ & 0.58 & 0.028 & 0.034 & 0.83 & 0.023 & 0.038 & 0.61 & 0.027 & 0.04 & 0.68 & 0.15 & 0.029 & 0.025 & 1.23 & 0.015 & 0.027 & 0.57 & 0.007 & 0.024 & 0.31 \\
\hline $35-44$ & 0.54 & 0.042 & 0.04 & 1.02 & 0.046 & 0.04 & 1.12 & 0.05 & 0.048 & 1.01 & 0.11 & 0.01 & 0.02 & 0.5 & -0.01 & 0.019 & -0.5 & -0.007 & 0.019 & -0.35 \\
\hline $45-54$ & 0.47 & -0.035 & 0.051 & -0.7 & -0.032 & 0.0511 & -0.63 & 0.028 & 0.511 & 0.55 & 0.08 & 0.001 & 0.015 & 0.08 & 0.004 & 0.016 & 0.25 & $-0.02^{*}$ & 0.009 & -1.79 \\
\hline $55+$ & 0.37 & 0.013 & 0.044 & 0.3 & -0.01 & 0.041 & -0.24 & -0.032 & 0.041 & -0.77 & 0.04 & 0.001 & 0.009 & 0.14 & -0.005 & 0.009 & -0.55 & -0.003 & 0.008 & -0.43 \\
\hline All adults & 0.5 & 0.016 & 0.028 & 0.59 & 0.002 & 0.03 & 0.1 & 0.001 & 0.029 & 0.04 & 0.11 & 0.005 & 0.009 & 0.57 & 0.002 & 0.011 & 0.24 & -0.002 & 0.009 & -0.3 \\
\hline \multicolumn{21}{|c|}{ Self-employed/family business } \\
\hline $18-24$ & 0.31 & -0.02 & 0.03 & -0.64 & -0.01 & 0.033 & -0.3 & 0.009 & 0.035 & 0.29 & 0.11 & 0.013 & 0.021 & -0.7 & -0.016 & 0.014 & -1.01 & -0.019 & 0.016 & -1.08 \\
\hline $25-34$ & 0.38 & -0.043 & 0.029 & -1.41 & -0.052 & 0.031 & -1.57 & -0.019 & 0.036 & -0.52 & 0.16 & 0 & 0.021 & -0.04 & 0.025 & 0.027 & 1.01 & -0.015 & 0.02 & -0.71 \\
\hline $35-44$ & 0.42 & -0.054 & 0.037 & -1.42 & -0.046 & 0.037 & -1.2 & -0.037 & 0.045 & -0.8 & 0.18 & -0.015 & 0.023 & -0.62 & 0.021 & 0.025 & 0.81 & $-0.044^{*}$ & 0.02 & -1.85 \\
\hline $45-54$ & 0.49 & 0.01 & 0.046 & 0.22 & 0.02 & 0.047 & 0.43 & -0.009 & 0.048 & -0.18 & 0.17 & 0.011 & 0.023 & 0.49 & 0.006 & 0.021 & 0.3 & -0.002 & 0.02 & -0.14 \\
\hline $55+$ & 0.51 & -0.017 & 0.038 & -0.45 & -0.01 & 0.038 & -0.27 & 0.021 & 0.039 & 0.54 & 0.18 & $-0.026^{*}$ & 0.012 & -1.89 & -0.02 & 0.014 & -1.28 & -0.026 & 0.015 & -1.47 \\
\hline All adults & 0.42 & -0.026 & 0.024 & -1.06 & -0.02 & 0.025 & -0.79 & -0.002 & 0.027 & -0.1 & 0.16 & -0.005 & 0.012 & -0.45 & -0.001 & 0.012 & -0.14 & -0.022 & 0.011 & -1.85 \\
\hline
\end{tabular}

***=significant at 1\% level, ${ }^{* *=s i g n i f i c a n t ~ a t ~ 5 \% ~ l e v e l, ~ *=s i g n i f i c a n t ~ a t ~} 10 \%$ level

See text for more details 
Table 3 - The impact of PROGRESA on leisure time of program eligible $(E=1)$ adults

\begin{tabular}{|c|c|c|c|c|c|c|c|c|}
\hline \multirow{3}{*}{ Age group } & \multirow{3}{*}{$\begin{array}{l}\text { Pre-prog } \\
\text { daily } \\
\text { hours }\end{array}$} & \multirow{2}{*}{\multicolumn{3}{|c|}{$\begin{array}{c}\text { Men } \\
\text { Impact } \\
\text { Jun-99 }\end{array}$}} & \multirow{3}{*}{$\begin{array}{l}\text { Pre-prog } \\
\text { daily hours }\end{array}$} & \multicolumn{3}{|c|}{$\begin{array}{c}\text { Women } \\
\text { Impact }\end{array}$} \\
\hline & & & & & & \multicolumn{3}{|c|}{ Jun-99 } \\
\hline & & coef. & se & t-stat & & coef. & se & t-stat \\
\hline $18-24$ & 16.24 & $-0.321^{*}$ & 0.169 & -1.9 & 17.18 & 0.026 & 0.087 & 0.3 \\
\hline $25-34$ & 14.69 & 0.122 & 0.122 & 1 & 16.17 & -0.236 & 0.148 & -1.6 \\
\hline $35-44$ & 14.64 & -0.061 & 0.087 & -0.7 & 16.65 & -0.016 & 0.160 & -0.1 \\
\hline $45-54$ & 14.72 & 0.06 & 0.200 & 0.3 & 17.44 & 0.023 & -0.230 & -0.1 \\
\hline $55+$ & 16.63 & -0.144 & 0.206 & -0.7 & 19.21 & 0.09 & 0.150 & 0.6 \\
\hline
\end{tabular}

*=significant at $10 \%$ level 
Table 4: Poverty measures and 2DIF estimates of PROGRESA impact on poverty

\begin{tabular}{|c|c|c|c|c|c|c|c|c|c|c|c|c|c|}
\hline \multirow{2}{*}{\multicolumn{2}{|c|}{ Poverty measure }} & \multicolumn{6}{|c|}{ Poverty line: Canasta basica in Nov 97} & \multicolumn{6}{|c|}{$\begin{array}{c}\text { Poverty line: Median of Nov } 98 \text { Consumption p.c. } \\
\text { 2DIF }\end{array}$} \\
\hline & & Mean & s.e & Impact & $\%$ & s.e. & $t$ & Mean & s.e & Impact & $\%$ & s.e. & $t$ \\
\hline \multicolumn{14}{|c|}{ Head Count Ratio } \\
\hline Nov-97 & Control & 0.901 & 0.007 & & & & & 0.590 & 0.014 & & & & \\
\hline Nov-97 & Treatment & 0.896 & 0.005 & & & & & 0.609 & 0.011 & & & & \\
\hline Nov-98 & Control & 0.911 & 0.007 & & & & & 0.627 & 0.018 & & & & \\
\hline Nov-98 & Treatment & 0.908 & 0.005 & -0.001 & -0.08 & 0.006 & -0.18 & 0.602 & 0.012 & -0.044 & -7.22 & 0.014 & -3.01 \\
\hline Jun-99 & Control & 0.933 & 0.004 & & & & & 0.656 & 0.013 & & & & \\
\hline Jun-99 & Treatment & 0.921 & 0.004 & -0.038 & -0.71 & 0.006 & -3.85 & 0.627 & 0.010 & -0.063 & -10.34 & 0.013 & -4.85 \\
\hline Nov-99 & Control & 0.920 & 0.006 & & & & & 0.645 & 0.017 & & & & \\
\hline Nov-99 & Treatment & 0.897 & 0.005 & -0.014 & -1.25 & 0.005 & -4.63 & 0.516 & 0.011 & -0.066 & -10.83 & 0.012 & -5.22 \\
\hline \multicolumn{14}{|c|}{ Poverty Gap } \\
\hline Nov-97 & control & 0.541 & 0.009 & & & & & 0.272 & 0.009 & & & & \\
\hline Nov-97 & treatment & 0.560 & 0.008 & & & & & 0.308 & 0.011 & & & & \\
\hline Nov-98 & control & 0.576 & 0.012 & & & & & 0.316 & 0.012 & & & & \\
\hline Nov-98 & treatment & 0.555 & 0.008 & -0.070 & -12.5 & 0.007 & -0.96 & 0.287 & 0.009 & -0.048 & -15.58 & 0.013 & -3.54 \\
\hline Jun-99 & control & 0.627 & 0.008 & & & & & 0.393 & 0.010 & & & & \\
\hline Jun-99 & treatment & 0.587 & 0.007 & -0.057 & -10.17 & 0.010 & -5.68 & 0.331 & 0.008 & -0.096 & -31.16 & 0.013 & -7.36 \\
\hline Nov-99 & control & 0.569 & 0.011 & & & & & 0.299 & 0.010 & & & & \\
\hline Nov-99 & treatment & 0.490 & 0.006 & -0.080 & -14.28 & 0.011 & -6.98 & 0.197 & 0.005 & -0.103 & -33.44 & 0.012 & -8.04 \\
\hline \multicolumn{14}{|c|}{ Squared Poverty Gap } \\
\hline Nov-97 & control & 0.379 & 0.009 & & & & & 0.177 & 0.008 & & & & \\
\hline Nov-97 & treatment & 0.407 & 0.010 & & & & & 0.215 & 0.011 & & & & \\
\hline Nov-98 & control & 0.418 & 0.012 & & & & & 0.216 & 0.011 & & & & \\
\hline Nov-98 & treatment & 0.392 & 0.008 & -0.018 & -4.42 & 0.007 & -2.64 & 0.187 & 0.008 & -0.148 & -68.83 & 0.016 & -9.14 \\
\hline Jun-99 & control & 0.485 & 0.009 & & & & & 0.299 & 0.008 & & & & \\
\hline Jun-99 & treatment & 0.432 & 0.007 & -0.097 & -23.83 & 0.011 & -8.63 & 0.233 & 0.008 & -0.136 & -63.25 & 0.015 & -9.05 \\
\hline Nov-99 & control & 0.406 & 0.010 & & & & & 0.196 & 0.008 & & & & \\
\hline Nov-99 & treatment & 0.316 & 0.005 & --0.117 & -28.74 & 0.013 & -8.98 & 0.114 & 0.004 & -0.119 & -55.34 & 0.014 & -8.05 \\
\hline
\end{tabular}


Figure 1 - Mean household income from children

Among beneficiary households with children aged 8-17

Panel a

Mean household TOTAL income from Children

(excluding PROGRESA cash transfer)

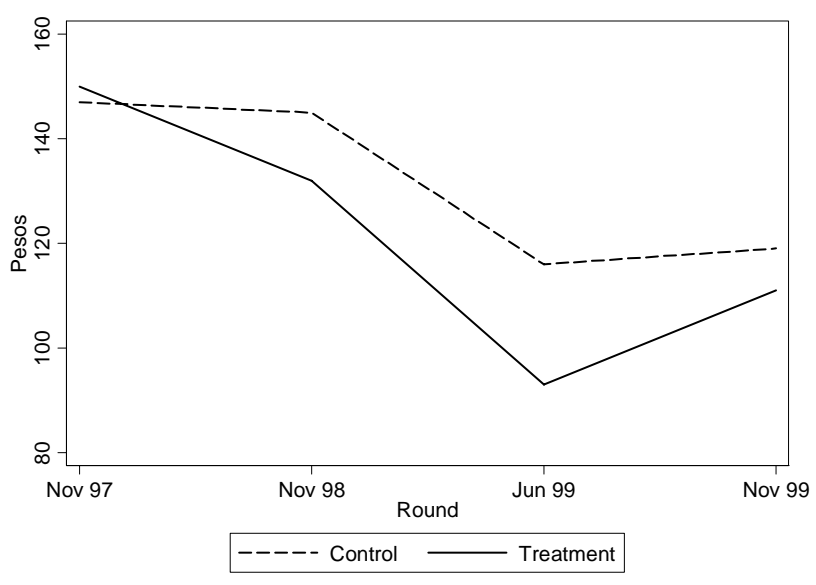

Panel $b$

Mean household LABOR income from Children

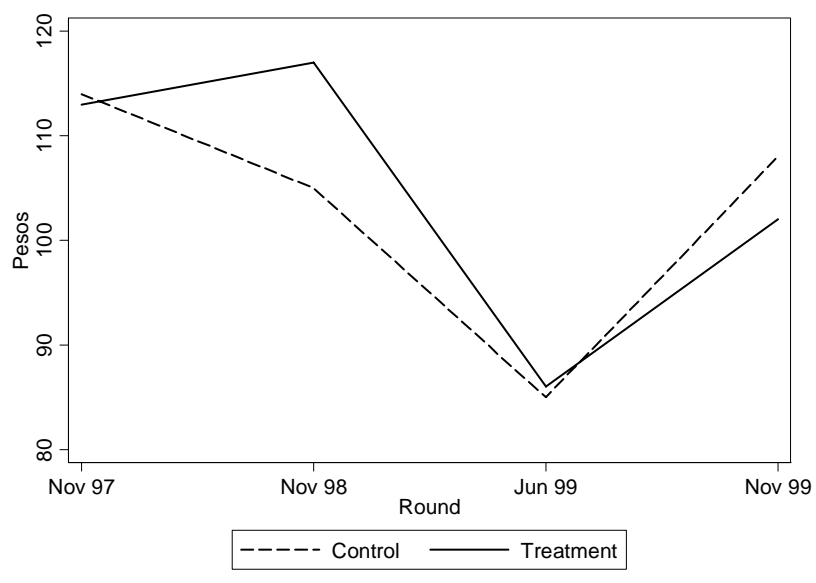

Panel c

Mean household OTHER INCOME from Children

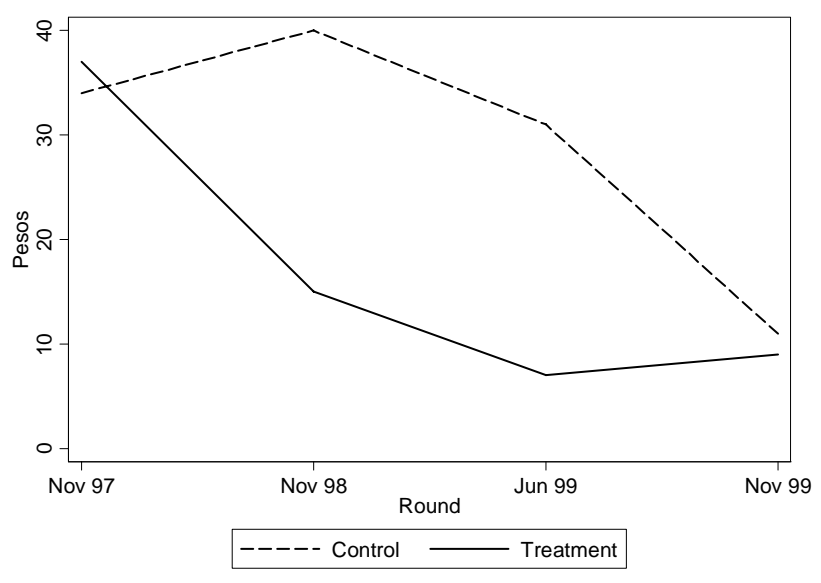


Figure 2

Percentages of Households in Treatment Localities that Receive the Transfers from Other Programs and PROGRESA

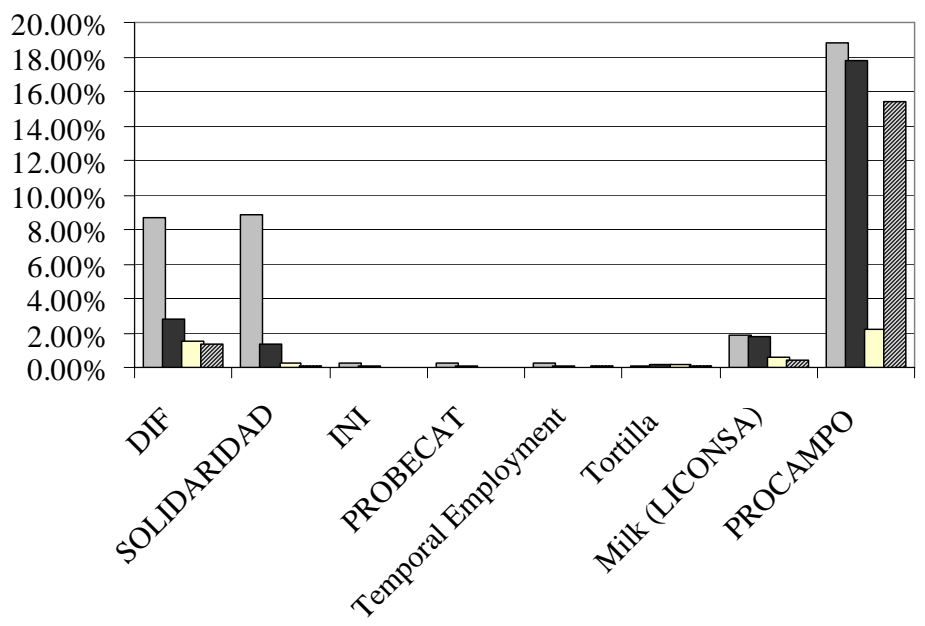

$\square$ Nov-97 $\square$ Nov-98 $\square$ Jun-99 $\square$ Nov-99 
Figure 3 - Estimated Distribution Function and Poverty Deficit Curve $x$-variable is income
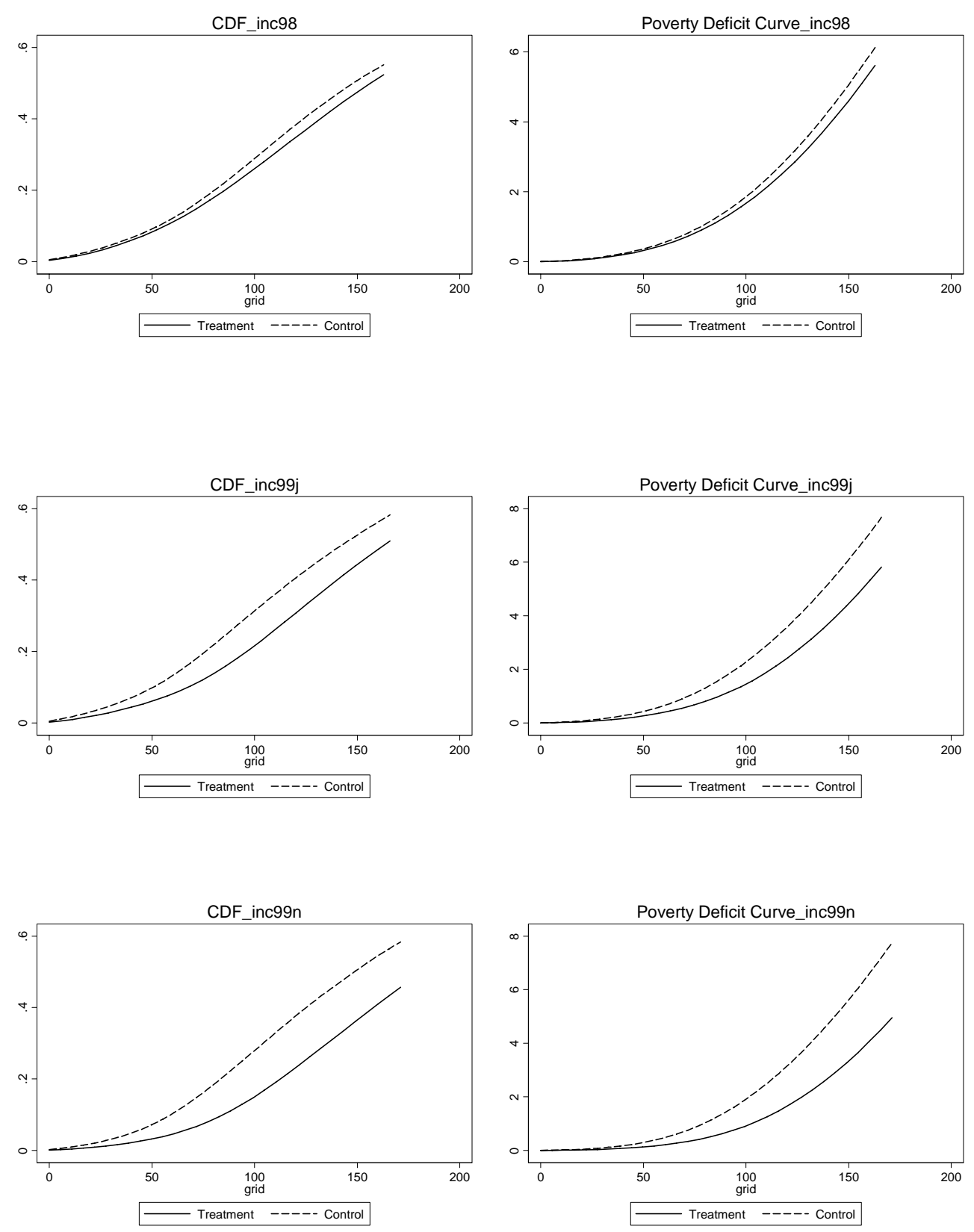
Appendix A: Test of Stochastic dominance and poverty ${ }^{19}$

Consider two distributions of welfare indicators with cumulative distribution functions, FA and $\mathrm{F} B$, with support in the nonnegative real numbers. Let

$$
D_{A}^{1}(x)=F_{A}(x)=\int_{0}^{x} F_{A}(x)
$$

If $D_{A}^{1}(x) \leq D_{B}^{1}(x)$ for all $+x \in \Re$ (i.e. $F_{A}$ is everywhere to the right of $F_{B}$ ), then distribution $A$ is said to (strictly) first order dominate distribution $B$. In terms of welfare economics, the interpretation is that up to the poverty line $x, A$ is a better distribution than $B$ for any welfare function that is both increasing in the welfare variable (e.g. expenditures) and anonymous, in the sense that we do not care that one particular person's welfare falls, as long as another's rises by more than enough to compensate. If we can say this for a broad range of poverty lines, then we have a quite general conclusion that $A$ is preferable to $B$. Since $D_{A}^{1}(x)$ is also the poverty headcount ratio (P0) where the $x$ is the poverty line, it follows that first order dominance implies that poverty as measured by $\mathrm{P} 0$ is lower for distribution $A$ than for distribution $B$ regardless of the poverty line chosen. Dominance results can also be considered up to a maximum allowable poverty line if we are not concerned with relative changes in the upper ends of the distribution. If the two distributions cross within the range of poverty lines that we consider relevant, then first order dominance does not hold, and we know that different poverty lines and measures will rank the distributions differently. In other words, depending on the poverty line or measure chosen, we might simultaneously conclude that poverty increased or decreased. In this case, we can still make a fairly general welfare statement if second order dominance holds. In particular, if $A$ second-order dominates $B$, then $A$ is a better distribution than $B$ for all welfare functions that are

\footnotetext{
19 The Stata code for the stochastic dominance test and the material in this appendix is taken from David Stiffel's webpage and follow closely Ravallion (1994) and Davidson and Duclos (2000). \{see http://ww2.lafayette.edu/ stifeld/dsstata.html\#dom
} 
increasing, anonymous, and that favor equality. To define second-order dominance, let $D_{A}^{2}(x)$ be the area under $F_{A}$ up to $x$,

$$
D_{A}^{2}(x)=\int_{0}^{x} D_{A}^{1}(y) d y
$$

If $D_{A}^{2}(x) \leq D_{B}^{2}(x)$ for all $x$ (i.e. the area under $F_{A}$ up to $x$ is less the area under $F_{B}$ up to $x$ ), then distribution $A$ is said to (strictly) second order dominate distribution $B$. If, to use Ravallion's (1994) terminology, the "poverty deficit" curves ( D2 ) cross, then higher orders of dominance can be checked. To generalize, let

$$
D_{A}^{s}(x)=\int_{0}^{x} D_{A}^{s-1}(y) d y
$$

for any integer, $s \geq 2$. Now distribution $A$ is said to (strictly) dominate distribution $B$ at order $s$ if $D_{A}^{s}(x) \leq D_{B}^{s}(x)$.

Davidson and Duclos (2000) show that $D s(x)$ can be equivalently expressed as

$$
D^{s}(x)=\frac{1}{(s-1) !} \int_{0}^{x}(x-y)^{s-1} d F(y)
$$

This formulation makes it easy to see that second order dominance implies that the poverty gap ( P1) is less for distribution $A$ than for distribution $B$ for all possible poverty lines. Further, third order dominance implies an unambiguous change in the squared poverty gap ( P2 ). To generalize even further, welfare dominance of order s implies that the Foster-GreerThorbecke poverty measure $\mathrm{P}_{\mathrm{s}-1}$ is less for distribution $A$ than for distribution $B$ for all possible poverty lines. Foster and Shorrocks (1988) show that while first-order dominance is a sufficient condition for higher-order dominance, it is not a necessary condition. Thus if we find that a distribution first-order dominates another, then we know how poverty as measured by any of the FGT $\mathrm{P} a$ measures has changed over the relevant range of poverty lines. 
Davidson and Duclos (2000) also show that if we have a random sample of $N$ independent observations on the welfare variable, $y i$, from a population, then a natural estimator of $D^{s}(x)$ is

$$
D^{s}(x)=\frac{1}{N(s-1) !} \int_{0}^{x}(x-y)^{s-1} d \hat{F}(y)=\frac{1}{N(s-1) !} \sum_{i=1}^{N}(x-y)^{s-1} I\left(y_{i} \leq x\right)
$$

where $\hat{F}$ is the empirical cumulative distribution function of the sample, and $I(\cdot)$ is an indicator function, which is equal to one when it's argument is true, and equal to zero when false. We apply this estimator to two independent samples for each of our indicators. Thus the variance of the difference of the two estimators is,

$$
\operatorname{var}\left(\hat{D}_{A}^{s}(x)-\hat{D}_{B}^{s}(x)\right)=\operatorname{var}\left(\hat{D}_{A}^{s}(x)\right)+\operatorname{var}\left(\hat{D}_{B}^{s}(x)\right)
$$

which is easy to estimate since $\hat{D}^{s}(x)$ is a sum of iid variables. Simple $t$ statistics are constructed to test the null hypothesis,

$$
H_{0}: \hat{D}_{A}^{s}(x)-\hat{D}_{B}^{s}(x)=0
$$

for a series of test points up to an arbitrarily defined highest reasonable poverty line. In cases where the null hypothesis is rejected and the signs are the same on all of the $t$ statistics, then dominance of order $s$ is declared. The test takes also into account the clustered nature of our samples. 
Test results

$Z$ = grid point for income

D1 = statistics for distribution if households in treatment areas and poor

D2 = statistics for distribution if households in non treatment areas and poor

Nov 1999

Minimum test point is 22.631578

Maximum test point is 143.33333

order 1

$\begin{array}{rrrr}Z & \mathrm{D} 1 & \mathrm{D} 2 & \mathrm{t}-\text { statistic } \\ 22.63 & 0.08 & 0.12 & 3.21 \\ 28.98 & 0.10 & 0.13 & 2.40 \\ 35.34 & 0.11 & 0.13 & 1.56 \\ 41.69 & 0.13 & 0.14 & 0.94 \\ 48.04 & 0.14 & 0.15 & 0.82 \\ 54.40 & 0.16 & 0.17 & 0.82 \\ 60.75 & 0.17 & 0.19 & 1.14 \\ 67.10 & 0.19 & 0.21 & 1.29 \\ 73.45 & 0.21 & 0.23 & 0.87 \\ 79.81 & 0.23 & 0.25 & 0.71 \\ 86.16 & 0.26 & 0.28 & 1.30 \\ 92.51 & 0.28 & 0.30 & 1.03 \\ 98.86 & 0.30 & 0.32 & 0.55 \\ 105.22 & 0.34 & 0.37 & 1.78 \\ 111.57 & 0.36 & 0.39 & 1.33 \\ 117.92 & 0.38 & 0.41 & 1.05 \\ 124.28 & 0.41 & 0.44 & 1.46 \\ 130.63 & 0.44 & 0.47 & 1.70 \\ 136.98 & 0.46 & 0.50 & 1.72 \\ 143.33 & 0.49 & 0.52 & 1.48\end{array}$

Order 2

$\begin{array}{rrrr}Z & \mathrm{D} 1 & \mathrm{D} 2 & \mathrm{t}-\text { statistic } \\ 22.63 & 1.15 & 2.30 & 5.05 \\ 28.98 & 1.71 & 3.08 & 4.52 \\ 35.34 & 2.37 & 3.91 & 4.01 \\ 41.69 & 3.15 & 4.79 & 3.50 \\ 48.04 & 4.01 & 5.73 & 3.10 \\ 54.40 & 4.96 & 6.75 & 2.80 \\ 60.75 & 6.00 & 7.88 & 2.58 \\ 67.10 & 7.13 & 9.13 & 2.43 \\ 73.45 & 8.41 & 10.52 & 2.29 \\ 79.81 & 9.83 & 12.04 & 2.16 \\ 86.16 & 11.40 & 13.73 & 2.08 \\ 92.51 & 13.13 & 15.60 & 2.01 \\ 98.86 & 15.0 \odot & 17.57 & 1.93 \\ 105.22 & 17.05 & 19.84 & 1.92 \\ 111.57 & 19.26 & 22.25 & 1.91 \\ 117.92 & 21.62 & 24.78 & 1.88 \\ 124.28 & 24.15 & 27.51 & 1.86 \\ 130.63 & 26.85 & 30.47 & 1.88 \\ 136.98 & 29.71 & 33.58 & 1.88 \\ 143.33 & 32.72 & 36.82 & 1.88\end{array}$

order 3

$\begin{array}{rrrr}Z & \mathrm{D} 1 & \mathrm{D} 2 & \mathrm{t}-\text { statistic } \\ 22.63 & 10.89 & 24.48 & 5.52 \\ 28.98 & 19.91 & 41.56 & 5.23 \\ 35.34 & 32.82 & 63.76 & 4.91 \\ 41.69 & 50.33 & 91.36 & 4.57 \\ 48.04 & 73.05 & 124.71 & 4.24 \\ 54.40 & 101.51 & 164.29 & 3.94 \\ 60.75 & 136.29 & 210.72 & 3.68 \\ 67.10 & 177.93 & 264.70 & 3.45 \\ 73.45 & 227.21 & 327.05 & 3.26 \\ 79.81 & 285.06 & 398.63 & 3.10 \\ 86.16 & 352.41 & 480.38 & 2.95 \\ 92.51 & 430.24 & 573.48 & 2.83 \\ 98.86 & 519.53 & 678.79 & 2.72 \\ 105.22 & 621.25 & 797.41 & 2.62 \\ 111.57 & 736.53 & 931.05 & 2.55 \\ 117.92 & 866.31 & 1080.39 & 2.48\end{array}$




$\begin{array}{llll}124.28 & 1011.61 & 1246.36 & 2.42 \\ 130.63 & 1173.52 & 1430.43 & 2.37 \\ 136.98 & 1353.06 & 1633.74 & 2.32 \\ 143.33 & 1551.26 & 1857.31 & 2.29\end{array}$

Dominance achieved at order 3

June 1999

Minimum test point is 20.678703

Maximum test point is 130.96512

order 1

$\begin{array}{rrrr}Z & \mathrm{D} 1 & \mathrm{D} 2 & \mathrm{t}-\mathrm{stat} \text { stic } \\ 20.68 & 0.11 & 0.20 & 8.30 \\ 26.48 & 0.13 & 0.21 & 6.52 \\ 32.29 & 0.16 & 0.21 & 4.55 \\ 38.09 & 0.17 & 0.22 & 3.72 \\ 43.90 & 0.19 & 0.23 & 2.61 \\ 49.70 & 0.21 & 0.24 & 2.41 \\ 55.51 & 0.22 & 0.25 & 2.27 \\ 61.31 & 0.24 & 0.27 & 2.52 \\ 67.12 & 0.25 & 0.29 & 2.51 \\ 72.92 & 0.26 & 0.31 & 2.91 \\ 78.72 & 0.28 & 0.34 & 3.64 \\ 84.53 & 0.30 & 0.36 & 3.49 \\ 90.33 & 0.33 & 0.41 & 4.42 \\ 96.14 & 0.35 & 0.42 & 3.91 \\ 101.94 & 0.36 & 0.43 & 3.43 \\ 107.75 & 0.39 & 0.46 & 3.97 \\ 113.55 & 0.42 & 0.49 & 3.74 \\ 119.36 & 0.44 & 0.51 & 3.67 \\ 125.16 & 0.46 & 0.52 & 3.00 \\ 130.97 & 0.48 & 0.54 & 2.97\end{array}$

Dominance achieved at order 1

\section{Nov 1999}

Minimum test point is 25.789475 Maximum test point is 163.33334

order 1

$\begin{array}{rrrr}Z & D 1 & D 2 & t-s t a t i s t i c \\ 25.79 & 0.04 & 0.10 & 6.72 \\ 33.03 & 0.05 & 0.11 & 6.16 \\ 40.27 & 0.06 & 0.11 & 5.82 \\ 47.51 & 0.07 & 0.12 & 5.66 \\ 54.75 & 0.08 & 0.14 & 6.83 \\ 61.99 & 0.09 & 0.17 & 7.27 \\ 69.22 & 0.10 & 0.19 & 7.16 \\ 76.46 & 0.12 & 0.22 & 7.83 \\ 83.70 & 0.14 & 0.24 & 7.37 \\ 90.94 & 0.16 & 0.29 & 8.24 \\ 98.18 & 0.18 & 0.31 & 7.23 \\ 105.42 & 0.21 & 0.35 & 8.05 \\ 112.66 & 0.24 & 0.38 & 7.59 \\ 119.90 & 0.27 & 0.41 & 7.23 \\ 127.14 & 0.30 & 0.44 & 6.63 \\ 134.38 & 0.34 & 0.48 & 6.73 \\ 141.62 & 0.37 & 0.50 & 6.41 \\ 148.86 & 0.40 & 0.54 & 6.71 \\ 156.09 & 0.42 & 0.56 & 6.45 \\ 163.33 & 0.45 & 0.57 & 5.66\end{array}$

Dominance achieved at order 1 